\title{
Post-shipment financial flows in supply chains: A study of small- to medium-sized enterprise importers
}

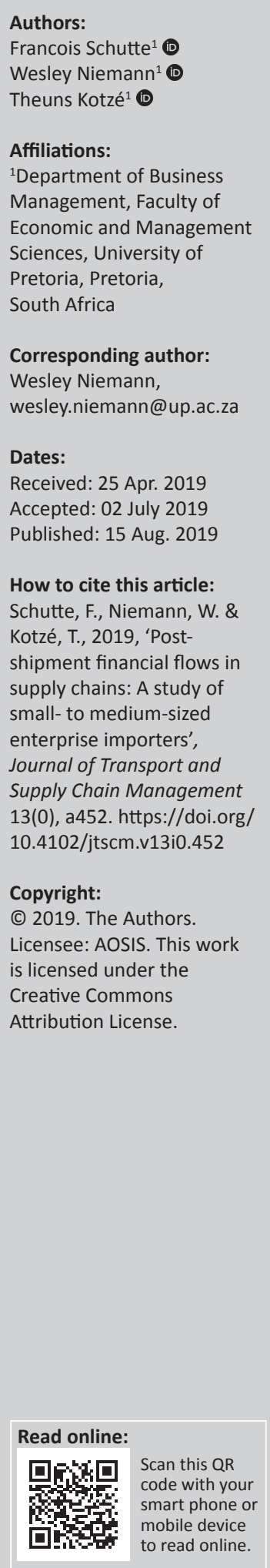

Background: Global sourcing has impacted inventory levels, lead times and the availability of working capital, affecting the standard financial flow of a supply chain. Poorly managing the link between the financial and physical supply chains could therefore lead to unnecessarily high inventory investments or to a short supply of inventory, affecting cash flow, working capital, sales and, subsequently, a firm's profitability.

Objectives: The aim of this generic qualitative study was to explore how firms manage their financial supply chain alongside their physical supply chain.

Method: Data were collected from 12 semi-structured interviews with senior managers across six small- to medium-sized enterprise (SME) importing firms in various industries.

Results: The research finds that the buyer is the driver of both upstream and downstream financial supply chain management (FSCM) as SME importers in Gauteng are proactively managing their financial alongside their physical supply chains. Through the continuous evaluation of sourcing strategies, exchange rate risk management strategies and inventory investment management strategies, firms can align their physical and financial supply chains.

Conclusion: This study highlights the lead time and disruption risks and costs of global sourcing and identifies FSCM tools that can be used to alleviate the financial burden associated with long lead times.

Keywords: financial supply chain management; post-shipment financial supply chain management; cash flow management; small- to medium-sized enterprises; qualitative research.

\section{Introduction}

Global sourcing affects cash flow when longer lead times and supply chain disruptions necessitate larger inventory levels (Aydin, Cattani \& Druehl 2014:454). Importers have therefore been forced to consider the net impact of cost advantages from sourcing globally compared to the relative cost of holding additional inventory (Jain, Girotra \& Netessine 2014:1203). The trade-off between holding additional inventory and the cost saving from sourcing globally introduces the need to manage the financial supply chain alongside the material flow of a supply chain. Financial supply chain management (FSCM) is the optimised planning, managing and controlling of supply chain cash flows to facilitate supply chain material flows (Wuttke, Blome \& Henke 2013:733).

Jain et al. (2014:1202-1222) focused on how importers manage inventory, and provided evidence that links global sourcing to an increase of $8.8 \%$ in inventory investment from a $10 \%$ increase in imports. This is supported by Aydin et al. (2014:454), who focused on the financial impact of global sourcing and its resulting higher inventory levels. Wuttke et al. (2013:773-789) extended the work of Aydin et al. (2014:454), presenting a framework that focused on the financial flows of supply chains and FSCM. This framework revealed that a weak working capital position pushes importers to focus on FSCM, where working capital management requires managing inventory, accounts receivable and cash flow balances in congruence with short-term credit to suppliers (Virgil 2013:146). Working capital management is defined as a firm's accounting strategy for the monitoring and utilisation of current assets and current liabilities to ensure efficient financial operation (Atrill \& McLaney 2015:330).

Two distinct, but not exclusive, FSCM categories were explored by Wuttke et al. (2013:773-789), namely pre- and post-shipment FSCM. Pre-shipment FSCM improves upstream supply chain working capital through reverse factoring, letters of credit (LC) or advance payments. 
Post-shipment FSCM strengthens the buyer's working capital position through trade finance (TF) agreements with financial services providers and customer payment term management (Famil \& Ali İhsan 2016:1-14). Wuttke et al. (2013:773-789) focused predominantly on pre-shipment FSCM, making the assumption that the buyer drives upstream FSCM. As there is little focus on post-shipment FSCM in their study, further research has been conducted to explore this topic and the practices importers use to manage financial outflows with suppliers and inflows with customers.

Virgil (2013:140-153) took a different approach to FSCM, seeking to optimise the supply chain for cash flow, as a new solution for supply chain resilience. This is done through the negotiation of payment terms with suppliers, financial institutions and customers to create a more resilient financial supply chain. Scholars have recently begun to demonstrate how planning, managing and controlling financial supply chain flows can affect supply chain profitability (Liu \& Cruz 2012:55-67; Raghavan \& Mishra 2012:407-412). While studies show the effect FSCM has on a firm's profitability, they do not show how a firm links its FSCM practices to its physical supply chain practices (Wuttke et al. 2013:773-789).

Therefore, this generic qualitative study builds on the research of Wuttke et al. (2013:773-789) and responds to the current knowledge gap on post-shipment FSCM by assuming that the buyer is the driver of both upstream and downstream FSCM. Focusing on small- to medium-sized enterprise (SME) importers of various products in Gauteng, the study explores how they link FSCM to their physical supply chain to improve working capital. The focus on SME importers provided the best environment for this study, as these firms are most dramatically affected by global sourcing supply risks such as supplier reliability, fluctuating foreign currency, complicated and costly logistics and fluctuating foreign currency (Niemann, Kotzé \& Mannya 2018:4-5).

The following research questions (RQs) guided this study:

- How do SME importers manage their post-shipment financial supply chain with regard to short-term credit when funding the cost of imports from foreign suppliers?

- How do SME importers manage post-shipment financial supply chains to align their local customers' payment terms with their operating and cash flow cycles?

- Which post-shipment FSCM tools are SME importers currently using?

The contribution of this study is threefold. Firstly, it adds to academic research by expanding on the work of Wuttke et al. (2013:773-789) in the context of SME importers in Gauteng, who are affected by market conditions such as fluctuating exchange and rising interest rates (Davis \& Taha 2015:38-50). Secondly, it provides greater insight into the FSCM workings of SME importers who must contend with a weak currency and high import costs, compared to global markets (Matthee \& Heymans 2013:391-407). Thirdly, it assists managers by identifying FSCM tools used by SME importers across various industries, and describes their effectiveness in freeing up working capital. This information allows practitioners to further investigate the tools and test them on their own financial supply chain.

The remainder of this article is structured as follows. The environment in which the study was conducted is introduced in the literature review, which describes the effects of global sourcing on importers' inventory levels and specifically SMEs in Gauteng, South Africa. An analysis is included describing how working capital management can be achieved through cash flow management and specific FSCM tools. Thereafter, the methodology used in the study is presented, followed by the findings of the study, which are discussed in the context of the literature. Lastly, conclusions are formulated, including remarks on contributions, limitations and opportunities for further research.

\section{Literature review \\ The South African economy and small- to medium-sized enterprise importers}

The National Small Business Act, No. 102 of 1996, categorises smaller businesses into five different stages of development: (1) survivalist, (2) micro, (3) very small, (4) small and (5) medium-sized enterprises. This study includes only the latter two categories. Small businesses are registered entities operating on fixed business premises. They have a complex organisational structure, are owner-managed and may have a maximum of 100 employees. Medium-sized businesses differ only in that they can have up to a maximum of 200 employees (Malefane 2013:672).

With a high vulnerability to interest and foreign exchange risks, an increase in the targeted funds' rate by the United States Federal Reserve could result in massive challenges when funding the dollar-denominated debt associated with importing (South African Reserve Bank 2017:11). Not only does this affect larger businesses that have the capacity to fund their imports from cash flow, but it greatly affects smaller businesses that are dependent on financing (Kohler \& Saville 2011:468). Financial institutions regard SMEs as high risk because of their limited resources and production capacity, imperfect financial information and propensity to default on loans (Matthee \& Heymans 2013:397). Financial institutions investigate three broad risk categories prior to financing SMEs: market risk, performance risk and specific risk. Market risk comprises sub-elements such as exchange rate risk, sovereign risk and commodity price risk (Matthee \& Heymans 2013:397). Importing firms, for example, are at risk of their domestic currency depreciating between order placement and the final supplier payment due date. In South Africa, this risk is pronounced because of the extreme volatility of the rand (Matthee \& Heymans 2013:397). Performance risk entails supplier risk, buyer risk and settlement risk (Davids, Meyer \& Louw 2015:70-95). Smallto medium-sized enterprise-specific risks relate to industry competition, level of demand for their product and the 
industry in which the SME operates (Malefane 2013:671-690). These risks, and the factors discussed in the next section, affect a firm's ability to effectively manage its financial supply chain.

\section{Global sourcing}

Global sourcing is distinguishable from local or regional sourcing by exchange rate risk, longer distances, political or regulatory environments and cultural differences (Aydin et al. 2014:454). These factors increase the challenge associated with managing a global supply chain, introducing the need for a more strategic management approach (Calvo \& Mart 2016:440). Global sourcing requires higher inventory levels because of longer lead times (Boute \& Van Mieghem 2015:2085). Because the goods are purchased at reduced prices from global suppliers, the capital investment in inventory, and its associated financial burden, will either increase or decrease with global sourcing (Jain et al. 2014:1206). This depends on the scale of the cost saving compared to the cost of holding higher inventory levels (Boute \& Van Mieghem 2015:2080-2099; Jain et al. 2014: 1202-1222).

Two competing recommendations are introduced regarding global sourcing (Boute \& Van Mieghem 2015:2080-2099; Jain et al. 2014:1202-1222). At one end, theory suggests sourcing from a small supplier grouping to reduce unit and fixed costs, lowering inventory investments. At the other end, it recommends splitting orders among a larger group of diversified suppliers in different locations, with various lead times, leading to lower inventory levels and therefore lower inventory investments (Jain et al. 2014:1204).

Boute and Van Mieghem (2015:2080) propose that combining multiple sources, with different skills and advantages, is more beneficial than single sourcing. Jain et al. (2014:1203) found that the effect of higher inventory levels because of global sourcing outweighs the lower procurement cost, and thus state that supplier diversification to reduce inventory investment is the better option. While Calvo and Mart (2016:436-455) acknowledge that dual sourcing is the superior strategy, they contend that in the absence of production costs, firms should seek as much flexibility in their supply chain as possible. They argue that suppliers will respond differently to pricing strategies when they are aware that they are not being awarded the full volume of the order (Calvo \& Mart 2016:437). As a firm's purchase costs account for roughly $60 \%$ of its revenue, emphasis should be placed on managing the financial supply chain alongside the physical material flow in a supply chain, especially in terms of inventory holding (Aydin et al. 2014:455).

\section{Inventory management}

Research shows that inventory and strategic sourcing models can have a positive impact on a firm's financial position when financial flows are considered (Gupta \& Lei 2009:4-18; Liebl, Hartmann \& Feisel 2016:393-413; Raghavan \& Mishra
2012:407-412). Firms must, however, consider the factors that affect their financial position when sourcing globally. Minimising inventory levels becomes challenging, as longer lead times and higher variability force firms to hold more stock in case of production stops (Jain et al. 2014:1206). Virgil (2013:140-153) and Wuttke et al. (2013:773-789) acknowledge the higher levels of inventory investment associated with sourcing globally, but argue that by effectively running the financial supply chain alongside the physical supply chain, the cost of this can be negated. These varying perceptions emphasise the need to consider the extensive impact global sourcing has on inventory investment and to address the following when planning/managing inventory levels: (1) unit procurement costs, (2) lead times, (3) fixed order costs and (4) delivery reliability.

\section{Unit procurement costs}

A key driver of global sourcing is the cost advantage of global producers' lower labour costs, economies of scale, superior infrastructure and possible export incentives (Golini \& Kalchschmidt 2015:64-78). The associated reduction in unit prices may, however, affect a firm's sourcing strategy, leading to increased purchases. This results in higher stock holding costs and a possible mismatch with local demand, negating the positive impacts of sourcing globally (Golini \& Kalchschmidt 2015:64-78).

A diverse supplier base allows placing of varying order quantities across suppliers, depending on the relative prices and terms received from these suppliers (Jain et al. 2014:1205). This then lowers the procurement cost per unit. Alternatively, Jain et al. (2014:1205) and Calvo and Mart (2016:446) suggest that a less diverse supplier base allows a higher allocation of volume to a supplier, resulting in volume discounts and relational dynamics. Both supplier dispersion and relationship development can lead to lower procurement costs per unit, but the best strategy has not been determined conclusively.

\section{Lead times}

In the context of imports, lead time includes the time for production, cross-border transit by sea or air, customs clearance and local delivery (Pietersen \& Moyane 2015: 22-23). Extended lead time requires firms to hold higher inventory levels as on hand inventory must be increased to cover local demand during manufacturing and replenishment (Boute \& Van Mieghem 2015:2080-2099). While Jain et al. (2014:1202-1222) and Golini and Kalchschmidt (2015:64-78) agree that dual sourcing can decrease the average lead time and therefore reduce required safety stock levels, it is noted that dual sourcing is not always an option for importers (Aydin et al. 2014:453-457).

\section{Fixed order costs}

Global sourcing is associated with pre-order costs such as freight, documentation, customs clearance (duty and customs VAT [value-added tax]), agent and facility fees and terminal handling charges (Pietersen \& Moyane 2015:22-23). 
By reducing the supplier base, firms source larger volumes from suppliers, which then reduces fixed order costs but increases average inventory levels (Golini \& Kalchschmidt 2015:64-68). The economic order quantity model predicts that by lowering fixed order costs, firms will order frequent but smaller quantities, resulting in lower inventory levels and, consequently, lower levels of inventory investment (Gupta \& Lei 2009:11).

\section{Delivery reliability}

Sourcing globally is at risk of supply chain disruptions at origin such as labour strikes, natural disasters and political and economic unrest (Jain et al. 2014:1202). This can be coupled with congestion at ports, inclement weather at sea and undesired customs detentions (Pietersen \& Moyane 2015:22-23). These factors should all be considered in the demand-forecasting model of a firm. Delivery reliability concerns can be mitigated through dual or multi-sourcing (Boute \& Van Mieghem 2015:2080-2099). By diversifying sourcing, firms can shift their order base from a disrupted source to an unaffected source, reducing safety stock requirements and inventory investment (Golini \& Kalchschmidt 2015:64-78; Jain et al. 2014:1202-1222).

\section{Working capital management}

El-Maude and Shuaib (2016:12-22) define working capital as the revolving cycle of capital a firm uses to invest in current assets (i.e. assets that are expected to turn into cash within 1 year) and to settle current liabilities (i.e. liabilities that are repayable within 1 year). Tauringana and Afrifa (2013:453-469) use working capital as a measurement tool to determine liquidity by focusing on cash flow, inventory management, receivables and payables. Through this tool, they determine the funds required for day-to-day business expenditure requirements.

Balancing working capital can be challenging. If firms opt for high inventory levels and extended trade terms, they can accomplish high sales levels, but at a higher unit cost (Famil \& Ali İhsan 2016:2). Higher inventory levels tie up cash flow, but avoid possible stock-outs. Extended payment terms from suppliers assist cash flow, but can be costly depending on the economic climate. Alternatively, attempting to reduce accounts receivable through reduced terms for buyers and strict collection policies may cause firms to lose sales and therefore lose profits (Famil \& Ali İhsan 2016:2).

For firms in both developed and developing countries, the objective of working capital management is to ensure they have regular, sufficient and consistent cash flow to fund day-to-day activities (El-Maude \& Shuaib 2016:13). The way in which working capital is managed can have a significant impact on a firm's profitability and cash holdings (Famil \& Ali İhsan 2016:1-14; Frankel, Levy \& Shalev 2017:438-458). Inefficient management of working capital may lead to low levels of cash flow and the inevitable failure of the firm (El-Maude \& Shuaib 2016:13).

\section{Cash flow management}

While the responsibility for cash flow management lies with the finance department, the implications thereof affect a firm's entire physical and financial supply chain (Fields 2016:226; Sula 2015:74-77). Firms must therefore effectively manage their cash flow cycle, as depicted in Figure 1.

The financial flows of firms are divided into the operating cycle and the cash flow cycle. The former refers to time between delivery of the goods and the collection of cash receivable, while the latter refers to time between the payment date for inventory and the collection of cash receivable (Virgil 2013:142). Small- to medium-sized enterprise importers must also ensure they take external factors such as capital market conditions and interest rates into account when managing cash flow (Atrill \& McLaney 2015:420-454):

(1) Capital market conditions: The condition of a country's monetary market and political climate can influence the way a company finances its cash flow. As South Africa relies heavily on imports, exchange rate volatility has a severely negative impact on trade (Davis \& Taha 2015:39).

(2) Interest rate: This is considered an expense from an income tax and external financing perspective as it can be very costly (Fields 2016:246). Global debt levels have raised concerns about financial stability. At the forefront of this is the non-financial corporate sector, which is vulnerable to foreign exchange risks and interest rate changes, with SMEs being the most harshly affected (Matthee \& Heymans 2013:397; South African Reserve Bank 2017:12).

Balancing the operating and cash flow cycles with the internal or external financing available will shorten the cash flow cycle and therefore free up liquidity for the firm (Sula 2015:74-77; Virgil 2013:140-153). This is the essence of FSCM.

\section{Financial supply chain management}

Financial supply chain management 'parallels the physical supply chain and represents all the transactions and activities related to the flow of cash from a customer's initial order placement, through to the final payment of the seller' (Virgil 2013:143). This process is presented in Figure 2.

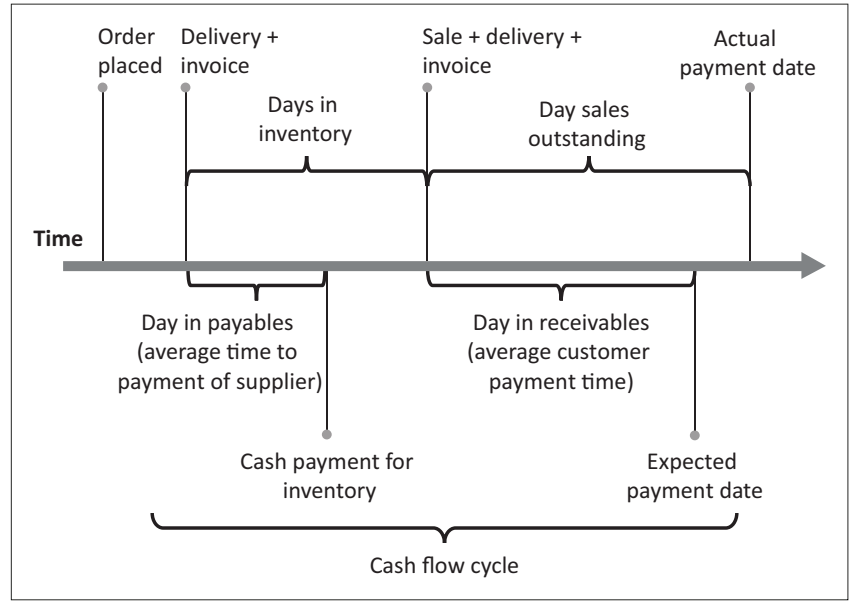

Source: Virgil, P., 2013, 'The financial supply chain management: A new solution for supply chain resilience', Bucharest Academy of Economic Studies, Faculty of Commerce 15(33), 146. FIGURE 1: The cash flow cycle of a firm. 


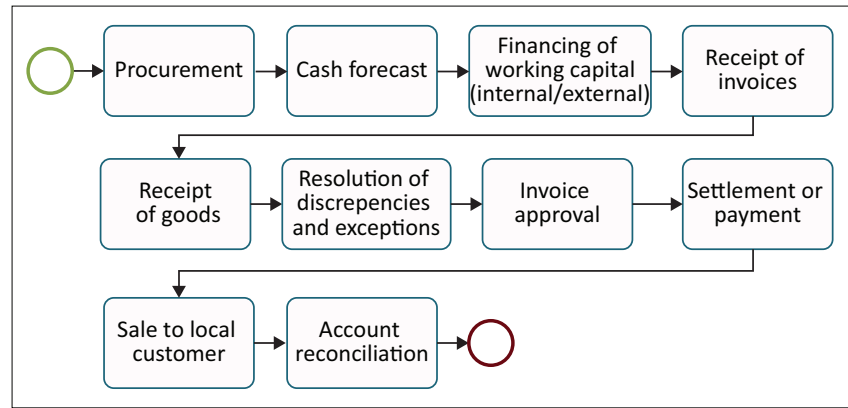

Source: Adapted from Virgil, P., 2013, 'The financial supply chain management: A new solution for supply chain resilience', Bucharest Academy of Economic Studies, Faculty of Commerce 15(33), 142 .

FIGURE 2: The purchase-to-pay process flow.

Because of the current global economic downturn (Osadchiy, Gaur \& Seshadri 2016:1755-1777), pressure is being placed on financial managers to develop methods to improve cash flow. The following two sections define pre- and post-shipment FSCM tools that assist with managing upstream and downstream financial supply chains.

\section{Pre-shipment financial supply chain management}

The aim hereof is to provide suppliers with adequate capital to ensure quality, timely production to minimise any possible lead time delays or quality assurance failures (Wuttke et al. 2013:773-789). This can be done using LC and advanced supplier payments.

Letters of credit: Kohler and Saville (2011:469) define LC as documentation issued by the importer's (i.e. buyer's) bank that acts as a means of assurance that the exporter (i.e. supplier) will be paid in full if it meets the requirements of the LC agreement. Once an LC is issued, the supplier can draw funds by providing the necessary documentation to the issuing bank.

Advance supplier payments: Cash in advance is a direct payment method that requires the buyer's internal funds to finance the transaction (Matthee \& Heymans 2013:394). This method is rarely used by SMEs as they seldom have access to large amounts of cash (Matthee \& Heymans 2013:391-407; Virgil 2013:140-153).

\section{Post-shipment financial supply chain management}

Post-shipment FSCM strengthens the importer's working capital position through TF agreements with financial services providers and other local financing techniques. These tools improve a firm's liquidity levels by not tying up its own funds in transactional stock while in production or in transit (Wuttke et al. 2013:773-789). The tools and their benefits are discussed next.

Trade finance: With TF, the importer uses documentation pertaining to the goods that the supplier has shipped to obtain funding from a domestic financial services provider who, in turn, finances the foreign currency value of the invoice (Frankel et al. 2017:438-458).
Debtors finance (accounts receivable financing): The importer pledges its accounts receivable to a financial institution to receive advance financing and repays the provider once it receives payment from its debtors. This provides the firm with its required working capital (Atrill \& McLaney 2015:210-217).

Clearing agent financing: Aside from the production cost of an imported product, there are various unknown costs associated with importing, including import duties, customs VAT, freight costs, customs clearing costs and local transportation costs from the port (Calvo \& Mart 2016:436-455; Osadchiy et al. 2016:1755-1777). Local clearing agents with their own customs and VAT deferments can outlay these costs on an importer's behalf, providing the importer with repayment terms that match its cash flow cycle. While there are costs involved with this financing tool, it is perfect for SMEs that do not have immediate cash available (Davis \& Taha 2015:38-50).

\section{Methodology Research design}

This study employed a generic qualitative research design (Kahlke 2014:40). By focusing on answering questions such as what, why and how the researcher linked the study to existing academic knowledge on the phenomenon under investigation (Neergaard et al. 2009:2). These questions were answered using verbally based representations of data, to derive meaning from the participants' perspectives and experiences (Creswell 2014:19; Ritchie et al. 2014:3). The resultant descriptive information assisted the researcher in addressing the knowledge gap identified regarding postshipment FSCM.

\section{Sampling}

The study was conducted across SME importers in Gauteng, South Africa, where the scope of research was not industry specific, but limited by the size of firms investigated. This design was justified as it was used to link a specific phenomenon with existing research through purposive and maximum variation sampling, as well as thematic analysis (Percy, Kostere \& Kostere 2015:76-77). The units of analysis were SME importers who met the required inclusion criteria. Twelve individuals, across six firms, participated in two semi-structured interviews per firm. Small- to medium-sized enterprises are registered entities operating on fixed business premises.

Purposive sampling in this specific context was done to add value to academic research by expanding on the work of Wuttke et al. (2013:773-789). The expansion came by focusing on SME importers in Gauteng, who are more harshly affected by changing market conditions than their larger competitors (Davis \& Taha 2015:38-50). The study used homogenous sampling at a firm level. Firms were homogenous in the following criteria. Each firm was based in Gauteng and was actively importing goods from one or more foreign suppliers. 
The firms were either small or medium in size. To provide flexibility and an in-depth understanding of the topic, the researcher sampled firms across various industries to ensure maximum variation. This gave the researcher multiple perspectives across firms with different sourcing and financing strategies, allowing the identification of common themes across a diversified sample (Polit \& Beck 2012:517).

As the research required the participation of individuals who possess similar characteristics, participants were sampled through homogenous purposeful sampling. The participants were supply chain managers, procurement managers, financial managers, financial directors or individuals who fulfilled these responsibilities internally. The supply chain managers or procurement managers were directly involved with the global sourcing, inventory management and import management of their supply chain. The financial managers or directors were directly involved with the payment of foreign suppliers, the management of accounts receivable and the management of working capital through the cash flow cycle. All participants had been employed by their firm for a minimum of 6 months at the time of the interview, to ensure data integrity. There were no requirements regarding age or gender of participants and each participant was interviewed separately to avoid biased responses. Table 1 presents the participants and their firms.

As the research used homogenous and maximum variation sampling, it followed the principle of data saturation (cf. Francis et al. 2010:1234). Guest, Bunce and Johnson (2006:65) define data saturation as the point at which no new information can be gained from further data collection and no new themes can be identified. A minimum sample size of five firms was investigated, with two participants from each firm being interviewed. Thereafter, two consecutive interviews, where no new themes emerged, were conducted to confirm data saturation.

\section{Data collection}

As mentioned, data were collected through 12 face-to-face, semi-structured interviews; two per participating firm. Rowley (2012:262) explains that for the novice researcher, a semi-structured interview with a detailed discussion guide is an excellent starting point for generic qualitative research, as the interviewer seeks to gather information on participants' experiences and opinions. The development of the discussion guide was led by the literature review. The first draft was critically evaluated by a qualitative methodologist and an experienced supply chain management academic after a pretest was conducted with two experienced practitioners (Merriam 2009:95). No major changes resulted from the pretests and evaluation.

Interviews were conducted and all participants were interviewed in meeting rooms within their respective establishments. The average interview length was $48 \mathrm{~min}$. Each interview began with a brief introduction to the purpose of the study and participants were assured of their anonymity and confidentiality. Each participant read and signed the informed consent form prior to answering any of the main questions. All 12 interviews were transcribed by the researcher within $48 \mathrm{~h}$ of completion.

\section{Data analysis}

Because of its flexibility, thematic analysis allowed the researcher to make sense of collective or shared meanings and experiences within the data. This allowed the researcher to identify, organise and understand themes within the data (Braun \& Clarke 2012:57). Following the guidelines set by Braun and Clarke (2012:57-71), the researcher familiarised himself with the data by carefully reading and analysing each transcript and listening to each audio recording. Initial inductive codes were generated from the data and used to code segments of text from the transcripts. All redundant codes were removed and similar codes were combined through an iterative analysis. The revised codes were grouped under descriptive and overarching themes that were reviewed against the transcripts to ensure they covered all the necessary data patterns.

\section{Trustworthiness}

According to Creswell (2007:209), at least two techniques must be used for research to comply with the required trustworthiness criteria. The first technique, used to confirm credibility and confirmability, was peer debriefing.

TABLE 1: Participant and firm profiles.

\begin{tabular}{llllll}
\hline Pseudonym & Role & Gender & Interview length (min) & Firm & Industry and firm size \\
\hline P1 & Finance & Male & 48 & Firm A & Corporate gifts and accessories (medium) \\
P2 & Supply chain & Male & 48 & Firm A & Corporate gifts and accessories (medium) \\
P3 & Supply chain & Male & 36 & Felding \& mining (small) & Welding \& mining (small) \\
P4 & Finance & Female & 52 & Firm B C & Information technology (small) \\
P5 & Finance & Male & 64 & Firm C & Information technology (small) \\
P6 & Supply chain & Male & 83 & Firm D & Manufacturing (medium) \\
P7 & Finance & Male & 38 & Firm D & Manufacturing (medium) \\
P8 & Supply chain & Male & 65 & Firm E & FMCG (small) \\
P9 & Finance & Male & 44 & Firm F & FMCG (small) \\
P10 & Supply chain & Male & 29 & Wholesale (small) & Wholesale (small) \\
P11 & Finance & Male & 29 & & Firm F \\
P12 & Supply chain & Male & & &
\end{tabular}

Interview average length: 48 minutes.

min., minutes. 
Consultations with a supply chain management academic and a methodology expert ensured all aspects of trustworthiness were addressed. The research process was enhanced by identifying potential pitfalls in the study's design and making corrections where necessary (Creswell 2007:208; Polit \& Beck 2012:594). This was coupled with adequately communicating participant anonymity and the lead researcher's independent status to ensure forthright and honest information from participants. Secondly, a detailed description of the participants, methodology, research sites and study contents ensured the transferability of the study (Creswell 2007:209; Polit \& Beck 2012:585-588). Through this detailed description and the credibility created by peer debriefing, the research can be deemed dependable.

\section{Ethical considerations}

The study received ethical clearance from the relevant research ethics committee at the University of Pretoria prior to data collection (approval no. 29258970/2017). An informed consent form was provided to each participant. It communicates the purpose of the study, the voluntary nature of participation and the assurance of data confidentiality and anonymity. Participant and firm names were replaced with pseudonyms to protect each participant's identity and ensure honest responses.

\section{Findings}

The analysis presented below shows how SME importers in Gauteng manage their physical alongside their financial supply chains to maximise operational functionality. Through three main themes and various sub-themes, the research addresses the specific challenges faced by importers. These are presented by the state of the South African economy, global sourcing strategies, inventory management, cash flow management, working capital management and postshipment FSCM. Figure 3 shows the link between the main themes, sub-themes and RQs.

\section{Short-term credit when funding the cost of imports from foreign suppliers}

Theme 1 identifies how SME importers manage their postshipment financial supply chain with regard to short-term

\begin{tabular}{|c|c|c|}
\hline \multicolumn{3}{|c|}{ Post-shipment financial flows in supply chains } \\
\hline $\begin{array}{l}\text { Theme } 1 \text { (RQ1): } \\
\text { Short-term credit } \\
\text { when funding the } \\
\text { cost of imports }\end{array}$ & $\begin{array}{c}\text { Theme } 2 \text { (RQ2): } \\
\text { Aligning customer } \\
\text { payment terms with the } \\
\text { operating and cash flow cycle }\end{array}$ & $\begin{array}{c}\text { Theme } 3 \text { (RQ3): } \\
\text { Post-shipment } \\
\text { financial supply chain } \\
\text { management tools }\end{array}$ \\
\hline $\begin{array}{l}\text { - Financial supply } \\
\text { chain performance } \\
\text { evaluation } \\
\text { - Physical supply } \\
\text { chain performance } \\
\text { evaluation }\end{array}$ & $\begin{array}{l}\text { - Default customer } \\
\text { payment terms } \\
\text { - Positive alignment of cash } \\
\text { receivables through profit } \\
\text { margin management }\end{array}$ & $\begin{array}{l}\text { - Debtors finance } \\
\text { - Trade finance } \\
\text { - Clearing agent } \\
\text { financing }\end{array}$ \\
\hline
\end{tabular}

FIGURE 3: Post-shipment financial flows in supply chains. credit when funding the cost of imports from foreign suppliers. Wuttke et al. (2013:773-789) present a framework, which reveals that a weak working capital position pushes importers to focus on FSCM. While the research did not confirm this, it notes that SME importers in Gauteng are continuously evaluating both their financial and physical supply chains, regardless of their working capital position.

\section{Financial supply chain performance evaluation}

The research found that SME importers in Gauteng are addressing aspects of sourcing, exchange rate volatility, inventory holding costs and working capital management when evaluating the financial performance of their supply chains. While the dual sourcing strategies presented by Boute and Van Mieghem (2015:2080) may assist with reducing inventory levels, the research finds that the approach to pricing strategies presented by Calvo and Mart (2016:437) is more crucial to SME importers in Gauteng. Participating firms were found to use business relationships and purchase volumes to negotiate both pricing and payment terms with foreign suppliers:

'What we did was that we started out by creating a form of dependency on supplying us and then once you have your foot in the door there, then you can start negotiating. Based on that relationship and the loyalty, you have room to negotiate and then we asked if they could provide us with better payment terms.' (P9, male, finance)

'The margin is primarily from our negotiations with the supplier on the cost of the products. We buy high volume ...' (P8, male, supply chain)

'Some of the deals are big in volume terms ... manufacturing is 3-4 weeks and 5 weeks on the water. We think 30 days would be unfair because by the time the payment is due, the vessel is still on the water. In those instances, we would reach out for extended credit.' (P6, male, supply chain)

While extended payment terms from suppliers can assist with the financial burden associated with the long lead times attributed to global sourcing, importing firms are at risk of their domestic currency depreciating between order placement and the final supplier payment due date. In South Africa, this is a pronounced risk because of the extreme volatility of the rand (Matthee \& Heymans 2013:397). The effective management of exchange rate risks was addressed by 10 of the 12 research participants, confirming the volatility of the rand:

'Receive it now, the exchange rate is good, in a month's time, it tanks. I find it a bit riskier on the 30-day payments, especially when the South African market is what it is ...' (P3, male, supply chain).

'That is why we base our costing on the exchange rate which we have secured.' (P9, male, finance)

The associated reduction in unit price from high-volume purchases may affect a firm's sourcing strategy, leading them to purchase more. This results in higher stock holding costs and a possible mismatch with local demand, negating the positive impact of sourcing globally (Golini \& Kalchschmidt 2015:64-78). This was found in only one of the six participating 
firms and can be attributed to the entrepreneurial nature of the owners:

'Instead of USD100 you are paying USD50 per unit ... it is not a benefit really because you sit for a year with the stock and you have invested a lot of money ... then you are tying up your working capital.' (P7, male, finance)

Virgil (2013:140-153) and Wuttke et al. (2013:773-789) acknowledge the inventory investment associated with sourcing globally, but argue that by effectively running the financial alongside the physical supply chain, the cost implications can be negated. The research agrees with their argument, as only one firm addressed the cash flow implications of holding higher inventory levels. The same firm, however, sees these costs as advantageous, citing them as a barrier to entry for potential competitors:

'The plan is to have one month of orders in the warehouse, one month on the water and one month in manufacturing.' (P3, male, supply chain)

'It's a nice barrier to entry, the holding cost of stock ... you need a massive amount of capital to try and break in.' (P2, male, supply chain)

For firms in developed and developing countries, the objective of working capital management is to ensure regular and consistent cash flow to fund day-to-day activities (El-Maude \& Shuaib 2016:13). The research finds that SME importers are finding unique methods to manage their working capital position to maximise cash flow. These methods range from customer funding and customs VAT management, to clearing agent facility management:

'To get a facility for R130 million to raise LCs it is very difficult because we don't have that kind of muscle, but we can have it through these channels as the customer pays us and we use it as a guarantee.' (P7, male, finance)

'We are doing a VAT [value-added tax] return every month so it does help the cash flow that you are not waiting two months to recover VAT. But all the other clearing costs are factored into our selling cost to the customer.' (P4, female, finance)

'We pay our clearing agent on 7 days for 10 months of the year to minimise costs ... then to maximise cash flow, when we get to August/September/October, I'll take 30 days from statement.' (P2, male, supply chain)

\section{Physical supply chain performance evaluation}

Two sourcing strategies are presented in the research. At one end, theory suggests sourcing from a small supplier base, therefore reducing unit and fixed costs as well as lowering inventory investments. At the other end, it recommends splitting orders among a larger group of diversified suppliers in different locations, with various lead times, leading to lower inventory levels and therefore lower inventory investments (Jain et al. 2014:1204). The findings introduce the use of sourcing agents, who act as one point of contact to reduce fixed costs, but spread delivery reliability risk across a large supplier base:

'We work with one supplier in a sense that can procure from 100 suppliers who ship to us on a drop shipment basis so it doesn't impact the logistics.' (P6, male, supply chain)
By diversifying sourcing, firms can shift their order base from a disrupted source to an unaffected source, thereby reducing safety stock requirements and required inventory investment (Golini \& Kalchschmidt 2015:64-78). Statement by participant:

'What we are doing is we are diversifying to an extent. By not having the same geographical areas, if the one cannot supply, the other can.' (P9, male, finance)

By reducing the supplier base, a firm sources larger volumes from each supplier, which, in turn, reduces fixed order costs but increases average inventory levels (Golini \& Kalchschmidt 2015:64-68). Statement by participant:

'We are bringing in lots of containers and we negotiate for favourable costs. The cost from the supplier will be lower and the cost from our agencies will be lower.' (P8, male, supply chain)

Because of the global economic downturn (Osadchiy et al. 2016:1755-1777), pressure is being placed on financial managers to develop methods of improving a firm's cash flow. The research finds that SME importers in Gauteng are balancing aspects of their physical supply chain with their financial supply chain to manage the local and foreign costs associated with importing:

'We generally go for a 7-day account because we don't want to pay interest. But sometimes we go on to a 30-day account and are prepared to pay that interest to get the cash flow for the period.' (P1, male, finance)

'Time to time we will request extended terms ... to align the payment to the clearing agent with our accounts receivables.' (P6, male, supply chain)

Besides supplier cost, there are various costs associated with importing cargo (Calvo \& Mart 2016:436-455). It is crucial for managers to understand these costs and the financial strain they may have on a firm's cash flow. The quotations below confirm that SME importers in Gauteng have a sound understanding of the implications of these costs and how to manage them, even when they are not in control of the forwarding:

'Our suppliers pay for the freight and insurance, which minimises risk on our side. We make use of a well-known forwarding and clearing company. Cost-wise they are more efficient at a lower rate. It is minimal compared to what we would pay with anyone else, even a commercial bank.' (P9, male, finance)

'We have worked out that it's worth our while having a longer inventory holding time and bringing it in earlier than paying the surcharge on the goods landing in peak periods.' (P1, male, finance)

'We know that on a container ... the freight is going to be $15 \%$ of the commercial value, so when sending out our price lists, we take a three-month average of the exchange rate, add about a $2.5 \%$, base our prices on that, add the percentage of the shipping and then our margins accordingly.' (P3, male, supply chain)

'Clearing and forwarding ... we have chosen 7-day terms to keep the level of disbursement fee and cost of money fee the lowest 
we can. Our clearing agent could be our biggest creditor ... because of the high level of customs disbursements.' (P6, male, supply chain)

The research, therefore, finds that firms are using various sourcing, inventory management and payment term management strategies to manage their post-shipment financial supply chain with regard to short-term credit when funding the cost of imports from foreign suppliers.

\section{Aligning customer payment terms with the operating and cash flow cycle}

Theme 2 identifies how SME importers in Gauteng manage their post-shipment financial supply chains to align their local customers' payment terms with their operating and cash flow cycles. The financial flows of firms are divided into the operating cycle and the cash flow cycle. The former refers to the time between delivery of the goods and the collection of cash receivable, while the latter refers to the time between the payment date for inventory and cash receivables collection (Virgil 2013:142). The sub-themes below address two aspects of cash receivable management, namely default customer payment terms and the positive alignment of cash receivable through profit margin management.

\section{Default customer payment terms}

Attempting to reduce accounts receivable through reduced terms offered to buyers and strict collection policies may cause a firm to lose sales and therefore lose profits (Famil \& Ali İhsan 2016:2). The following quotations confirm that most participating firms are at the mercy of standard trading practices in South Africa when extending terms to local customers, and cannot therefore reduce accounts receivable:

'The vendor extends 30 days to the distributor; the distributor extends 30 days to the reseller and the reseller extends 30 days to the end user ... it is custom of trade.' (P6, male, supply chain)

'30 [D]ays is the norm in South Africa, so we just going along those lines.' (P3, male, supply chain)

'I would say it is an acceptable term, 30 days from date of statement in South Africa.' (P5, male, finance)

\section{Positive alignment of cash receivable through profit margin management}

If firms opt to have high inventory levels and extended trade terms, they can accomplish high sales levels, but at a higher unit cost (Famil \& Ali İhsan 2016:2). While this is found to be accurate, the standard approach to managing the misalignment between the participating firms' operating/ cash flow cycles and their cash receivable is to build a financing cost into the margins of the product:

'We have introduced stock to consignment to our biggest customers. So, it reduces our cash flow ... we have noticed that they have bought more from us because we have invested.' (P4, female, finance)

'They are not aligned as the customer has 60 days repayment term, but the margin we have created is sufficient to allow this.' (P5, male, finance)

\section{Post-shipment financial supply chain management tools}

Theme 3 identifies which post-shipment FSCM tools SME importers in Gauteng are currently using. Using postshipment FSCM tools, a firm can improve its liquidity levels by not having its own funds tied up in transactional stock while the goods are in production or transit (Wuttke et al. 2013:773-789). From the firm analysis, two participating firms made use of debtors finance and one firm implemented a TF product. Clearing agent financing was, however, used across all six participating firms.

\section{Debtors finance}

When using debtors finance, the importer pledges its accounts receivable to a financial institution and receives an advance. The capital amount is repaid once the firm receives payment from its debtors (Atrill \& McLaney 2015:210-217). While this tool provides importers with access to additional capital at a lower rate than an overdraft, it does not extend their working capital position to align the operational and cash flow cycle.

'So, it's at a better interest rate ... it will increase our access to additional funds.' (P1, male, finance)

'We were on R5.5 million. With debtor's finance ... they got us approved for like R12 million.' (P2, male, supply chain)

'Debtor finance for us is the best way. The one year we ... only used the facility twice. The thing is we always want that margin of safety.' (P5, male, finance)

\section{Trade finance}

When using $\mathrm{TF}$, the importer receives funding from a domestic financial services provider for the foreign currency value of the invoice. In turn, they are provided with repayment terms that match their cash flow cycle (Frankel et al. 2017:438-458). While only one participating firm used a TF product, the benefits thereof were clearly defined:

'Through trade finance there is pretty much no risk. Like I said, the payment terms from the supplier and payment terms from customers, it fills the whole gap. It comes at a slight additional cost ... which comes out break even with discounts from the supplier.' (P3, male, supply chain)

Figure 4 depicts firm B's cash flow and operating cycle prior to implementing a TF tool. It clearly shows that firm B has a misalignment between its operating and cash flow cycle. Funds are outlaid for a period of 63 days prior to receiving the stock, showing the long lead times associated with global sourcing. After receiving the stock, it takes an average of 66 days to receive payment from local customers. Therefore, firm $B$ requires enough cash flow to last an average of 129 days from order placement to cash receivable.

Figure 5 shows the improvement in firm B's cash flow and operating cycle once it began to use the TF tool. The supplier payment term was changed to $100 \%$ upfront, allowing firm B to negotiate an early settlement discount with suppliers. Firm B was then provided with 120 days to pay the TF service 


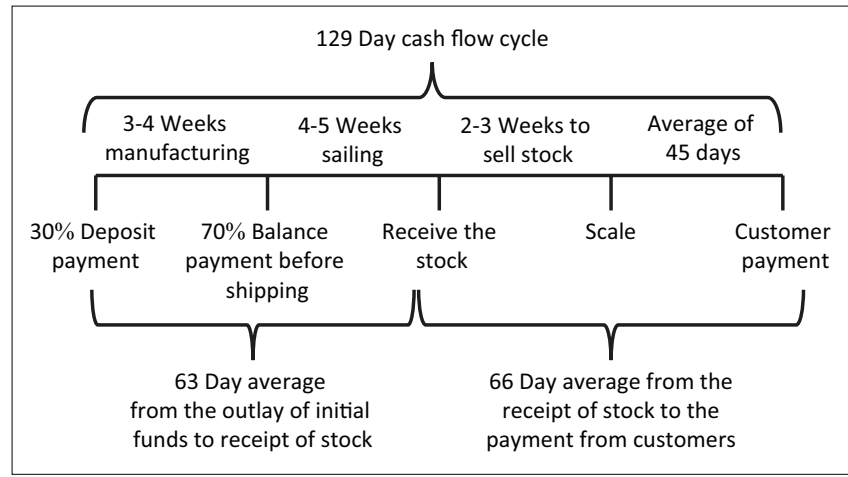

Source: Adapted from firm B's interviews.

FIGURE 4: The cash flow and operating cycle of firm B.

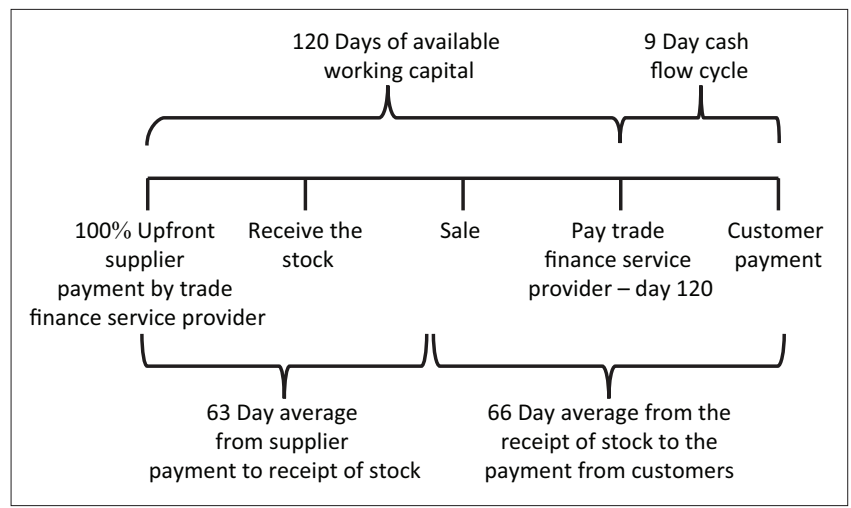

Source: Adapted from firm B's interviews

FIGURE 5: The introduction of trade finance into firm B's financial supply chain.

provider, reducing its cash flow requirement from 129 days to only 9 days, improving its working capital position and better aligning its operational and cash flow cycle.

\section{Clearing agent financing}

Local clearing agents with their own customs and VAT deferments outlay costs on an importer's behalf, giving the importer repayment terms that match its cash flow cycle. All the participating firms use clearing agent financing to better align their cash flow cycles when funding the cost of imports from foreign suppliers.

'A portion of the finance given to us has been allocated to clearing. Our stock will have the original landed cost, which is the foreign cost times the exchange rate, and then the additional cost would be your freight. The customs VAT portion goes through the VAT account and we claim that back.' (P3, male, supply chain)

'Customs VAT is so big for us that on our accounts we have a note that we are a R45-million-rand company, but what goes through our accounts is $\mathrm{R} 90$ million rand ...' (P5, male, finance).

'I will use the overdraft for the 7 days from invoice payments to the clearing agent.' (P2, male, supply chain)

\section{Conclusion}

\section{Summary of findings and theoretical implications}

The intent of the study was to build on the research of Wuttke et al. (2013:773-789) by exploring how SME importers in
Gauteng manage their physical alongside their financial supply chains. The first research question addresses how SME importers manage their post-shipment financial supply chain with regard to short-term credit when funding the cost of imports. Herein the study adds to the current literature by showing how firms link their FSCM practices to their physical supply chain practices. It is found that SME importers in Gauteng are continuously evaluating their physical and financial supply chains, regardless of their working capital positions.

By managing exchange rate risks, negotiating pricing and payment terms with suppliers and managing their working capital positions with localised techniques, the participating firms are effectively evaluating and managing their financial supply chains. By alternating sourcing strategies, managing inventory levels and understanding the financial implications of the costs associated with importing, the participating firms are effectively evaluating and managing their physical supply chains. Herein the study adds to the current literature presented by Jain et al. (2014:1202-1222) by introducing the concept of inventory holding costs, associated with global sourcing, acting as a barrier to entry for potential new market entrants.

The second research question investigates how SME importers in Gauteng manage their post-shipment financial supply chain with regard to aligning their local customer payment terms with their operating and cash flow cycles. The findings indicate that SME importers in South Africa are at the mercy of standard trading practices when extending terms to local customers. This misalignment between accounts payable and accounts receivable, coupled with the extended lead times of sourcing globally, places enormous strain on a firm's cash flow cycle. The findings, however, introduce the principle of aligning accounts receivable within the operating and cash flow cycles, by allocating a financing factor to profit margins to ease the financial burden.

The final research question identifies the current postshipment FSCM tools used by SME importers in Gauteng. The benefits of debtors finance are identified as providing access to additional capital at a minimal cost. However, this method provides little assistance in aligning the operational and cash flow cycle. Trade finance, on the contrary, is identified as a higher cost method, but shows a positive effect on a firm's working capital position, allowing it to align its cash flow and operational cycle.

Clearing agent financing was identified as a common method across all the participating firms. Through an extended payment term with clearing agents, firms can better align the gap created by long lead times and extended payment terms provided to customers. For SME importers, the use of a clearing agent is therefore crucial when managing the postshipment financial flows of their supply chains.

Based on the findings, buyers can, to an extent, manage payment terms and prices with their suppliers. While there is 
little control over the payment terms provided to customers, the FSCM tools identified above can assist with managing operational and cash flow cycles. The assumption that the buyer is the driver of both upstream and downstream FSCM is therefore found to be true.

\section{Managerial implications}

The findings of this study have four main managerial implications. Firstly, the findings contribute to the understanding of the benefits and pitfalls associated with extended payment terms provided by suppliers. While these terms may assist with the financial burden created by longer lead times, managers must ensure that they control the foreign exchange risks associated with the volatility of the South African rand. Taking precautionary measures, such as hedging the foreign exchange rate, allows firms to lock in their margins when selling their products locally.

Secondly, it is important for managers to note the opportunity costs associated with not holding stock. It is therefore crucial that firms not only diversify their sourcing to mitigate disruption risks, but also hold the correct levels of inventory for their forecast sales. While inventory holding can affect cash flow, having the stock on hand will ensure positive sales. It is also important for managers to consider the cost associated with holding inventory as a barrier to entry for competitors and use it to their advantage to gain further market share.

Thirdly, by understanding all the options of clearing agent financing, managers can minimise their financing costs by paying on a 7-day from invoice account during periods where the firm is cash positive. In periods where the firm does not have the cash funding necessary, they can request an extended term from their clearing agent to better align their operational and cash flow cycle.

Lastly, the research identifies the current post-shipment FSCM tools used by SME importers across various industries and their effectiveness in freeing up working capital. It is important that managers approach various financial institutions to investigate the suggested methods and create financial models to determine the benefits of each method for their financial supply chain.

\section{Limitations and directions for future research}

Despite contributing to the current literature by showing how importers link their FSCM practices with their physical supply chain practices, the findings are based on only six SME firms in Gauteng. As SME importers are predominantly owner-managed, with very few cross-functional silos, it would be beneficial for future research to target larger firms with specialised finance and supply chain departments. This will provide a holistic view of the post-shipment financial flows of importers and the communication between multiple departments to reach a common objective.
While the outcomes of the study are aligned with the research questions posed, it is recommended that a focus on one specific industry may result in greater uniformity across results. As firms in the same industry deal with similar supply chain risks, disruptions and challenges, it would be beneficial to analyse the post-shipment financial flows of their supply chains to determine if they are using similar management techniques and tools to align their operational and cash flow cycles.

Lastly, the research identifies a new field of thought in inventory management. Findings indicate that effectively managing the financial supply chain alongside the physical supply chain can reduce the financial burden of holding additional inventory when sourcing globally. While the costs of holding inventory can act as a barrier to entry for potential competitors, further research targeted at firms who stock products with long life cycles and have high inventory holding costs could contribute to the field of inventory management and economics.

\section{Acknowledgements Competing interests}

The authors declare that they have no financial or personal relationships that may have inappropriately influenced them in writing this article.

\section{Authors' contributions}

F.S. conducted the research as part of his MPhil degree. W.N. acted as supervisor of the research and prepared the manuscript. T.K. provided methodological and technical assistance.

\section{Funding information}

This research received no specific grant from any funding agency in the public, commercial or not-for-profit sectors.

\section{Data availability statement}

Data is stored in accordance with institutional policy.

\section{Disclaimer}

The views expressed in the submitted article are the authors' own and not an official position of the institution or funder.

\section{References}

Atrill, P. \& McLaney, E.J., 2015, Accounting and finance for non-specialists, 9th edn., Pearson, Harlow.

Aydin, G., Cattani, K. \& Druehl, C., 2014, 'Global supply chain management', Business Horizons 57(4), 453-457.

Boute, R.N. \& Van Mieghem, J.A., 2015 'Global dual sourcing and order smoothing: The impact of capacity and lead times', Management Science 61(9), 2080-2099. https://doi.org/10.1287/mnsc.2014.1992

Braun, V. \& Clarke, V., 2012, 'Thematic analysis', in H. Cooper (ed.), APA handbook of research methods in psychology, American Psychology Association, Washington, DC. 
Calvo, E. \& Mart, V., 2016, 'Sourcing strategies and supplier incentives for short-lifecycle goods' Management Science 62(2), 436-455, https://doi.org/10.1287/ cycle goods,
mnsc.2014.2138

Creswell, J.W., 2007, Qualitative inquiry \& research design: Choosing among five approaches, 2nd edn., Sage, Thousand Oaks, CA.

Creswell, J.W., 2014, Research design: Qualitative, quantitative, and mixed methods approaches, 4th edn., Sage, Thousand Oaks, CA.

Davids, P., Meyer, F.H. \& Louw, M., 2015, 'Evaluating the effect of proposed tariff protection for the South African broiler industry', Agrekon 54(1), 70-95. https:// doi.org/10.1080/03031853.2014.995190

Davis, C.G. \& Taha, F.A., 2015, 'The impact of exchange rate risk on Africa's imports of world poultry', Agrekon 54(2), 38-50. https://doi.org/10.1080/03031853.2015. 1072993

El-Maude, J.G. \& Shuaib, A.I., 2016, 'Empirical examination of the association of working capital management and firms' profitability of the listed food and beverages firms in Nigeria', Researchers World: Journal of Arts Science \& beverages firms in Nigeria', Researchers World: Journal of
Commerce 7(1), 12-22. https://doi.org/10.18843/rwjasc/v7i1/02

Famil, S.A.L. \& Ali ihsan, A.N., 2016, 'The relationship between working capital management and profitability: Evidence from Turkey', Business and
Economics Research Journal 7(2), 1-14. https://doi.org/10.20409/berj.2016 217492

Fields, E., 2016, The essentials of finance and accounting for nonfinancial managers, 3rd edn., American Management Association, New York.

Francis, J.J., Johnston, M., Robertson, C., Glidewell, L., Entwistle, V., Eccles, M.P. et al., 2010 , 'What is an adequate sample size? Operationalising data saturation for theory-based interview studies', Psychology \& Health 25(10), 1229-1245. https:// doi.org/10.1080/08870440903194015

Frankel, R., Levy, H. \& Shalev, R., 2017, 'Factors associated with the year-end decline in working capital', Management Science 63(2), 438-458. https://doi.org/10.1287/ mnsc.2015.2351

Golini, R. \& Kalchschmidt, M., 2015, 'Managing inventories in global sourcing contexts: A contingency perspective', International Journal of Production Economics 165 64-78. https://doi.org/10.1016/j.ijpe.2015.03.022

Guest, G., Bunce, A. \& Johnson, L., 2006, 'How many interviews are enough?', Field Methods 18(1), 59-82. https://doi.org/10.1177/1525822X05279903

Gupta, D. \& Lei, W., 2009, 'A stochastic inventory model with trade credit', Manufacturing and Service Operations Management 11(1), 4-18. https://doi. $\mathrm{org} / 10.1287 / \mathrm{msom} .1070 .0191$

Jain, N., Girotra, K. \& Netessine, S., 2014, 'Managing global sourcing: Inventory performance', Management Science 60(5), 1202-1222. http://doi.org/10.1287/ performance, $M$ mis.2013.1816
mnst

Kahlke, R.M., 2014, 'Generic qualitative approaches: Pitfalls and benefits of methodological mixology', International Journal of Qualitative Methods 13(1), 37-52. https://doi.org/10.1177/160940691401300119

Kohler, M. \& Saville, A., 2011, 'Measuring the impact of trade finance on country trade flows: A South African perspective', South African Journal of Economic and Management Sciences 14(4), 466-478.

Liebl, J., Hartmann, E. \& Feisel, E., 2016, 'Reverse factoring in the supply chain Objectives, antecedents and implementation barriers', International Journal of Physical Distribution and Logistics Management 46(4), 393-413. https://doi. org/10.1108/IJPDLM-08-2014-0171
Liu, Z. \& Cruz, J.M., 2012, 'Supply chain networks with corporate financial risks and trade credits under economic uncertainty', International Journal of Production Economics 137(1), 55-67. https://doi.org/10.1016/j.ijpe.2012.01.012

Malefane, S.R., 2013, 'Small, medium, and micro enterprise and local economic-base restructuring: A South African local government perspective', Journal of Public Administration 48(4), 671-690.

Matthee, M. \& Heymans, A., 2013, 'How South African SMEs can become better candidates for export finance', Managing Global Transitions 11(4), 391-407.

Merriam, S.B., 2009, Qualitative research: A guide to design and implementation, Jossey-Bass, San Francisco, CA.

Neergaard, M.A., Olesen, F., Andersen, R.S. \& Sondergaard, J., 2009, 'Qualitative description: The poor cousin of health research?', BMC Medical Research Methodology 9(1), 1-5. https://doi.org/10.1186/1471-2288-9-52

Niemann, W., Kotzé, T. \& Mannya, K., 2018, 'Global sourcing risk management approaches: A study of small clothing and textile retailers in Gauteng', Southern African Journal of Entrepreneurship and Small Business Management 10(1), 1-15. https://doi.org/10.4102/sajesbm.v10i1.141

Osadchiy, N., Gaur, V. \& Seshadri, S., 2016, 'Systematic risk in supply chain networks', Management Science 62(6), 1755-1777. https://doi.org/10.1287/mnsc.2015. 2187

Percy, W.H., Kostere, K. \& Kostere, S., 2015, 'Generic qualitative research in psychology', Qualitative Report 20(2), 76-85.

Pietersen, B. \& Moyane, T., 2015, 'Freight to the fore: Freight forwarding', Transport World Africa 13(6), 22-23.

Polit, D.F. \& Beck, C.T., 2012, Nursing research: Generating and assessing evidence for nursing practice, 9th edn., Wolters Kluwer Health, Philadelphia, PA.

Raghavan, N.R.S. \& Mishra, V.K., 2012, 'Short-term financing in a cash-constrained supply chain', International Journal of Production Economics 134(2), 407-412.

Ritchie, J., Lewis, J., McNaughton Nicholls, C. \& Ormston, R., 2014, Qualitative research practice: A guide for social science students and researchers, 2 nd edn., Sage, Los Angeles, CA.

Rowley, J., 2012, 'Conducting research interviews', Management Research Review 35(3-4), 260-271. https://doi.org/10.1108/01409171211210154

South Africa, 1996, The National Small Business Act, No. 102 of 1996

South African Reserve Bank, 2017, Financial stability review, viewed 12 May 2017 from https://www.resbank.co.za/Lists/News\%20and\%20Publications/Attachments/ 7786/First \%20edition\%20FSR\%20April\%202017.pdf.

Sula, V., 2015, 'Cash flows management at the enterprise level', Economy and Sociology 4(1), 74-77.

Tauringana, V. \& Afrifa, G.A., 2013, 'The relative importance of working capital management and its components to SMEs' profitability', Journal of Small Business and Enterprise Development 20(3), 453-469. https://doi.org/10.1108/JSBED-122011-0029

Virgil, P., 2013, 'The financial supply chain management: A new solution for supply chain resilience', Bucharest Academy of Economic Studies, Faculty of Commerce 15(33), 140-153.

Wuttke, D.A., Blome, C. \& Henke, M., 2013, 'Focusing the financial flow of supply chains: An empirical investigation of financial supply chain management', International Journal of Production Economics 145(2), 773-789. https://doi. org/10.1016/j.ijpe.2013.05.031 